\title{
Pengetahuan Ibu Menopause tentang Gizi Seimbang pada Masa Menopause di Wilayah Kerja Puskesmas Awang Besar, Barabai, Hulu Sungai Tengah
}

\author{
Riska Pebrianti' ${ }^{1}$ Ika Lestiani² \\ ${ }^{1}$ Puskesmas Hantakan Jl. Brigjen H. Hasan Basri, Hantakan, Hulu Sungai Tengah Provinsi Kalimantan Selatan \\ ${ }^{2}$ Akademi Kebidanan Banua Bina Husada Banjarbaru Jl. Mistar Cokrokusumo, Banjarbaru, \\ Provinsi Kalimantan Selatan \\ Email: febriiriska@gmail.com
}

\begin{abstract}
Abstrak
Wanita dianggap memasuki masa menopause jika wanita tersebut tidak mengalami menstruasi lagi dalam waktu 12 bulan tanpa disertai intervensi tertentu. Data dari wilyah kerja puskesmas Awang Besar Kabupaten Hulu Sungai Tengah pada tahun 2014 ada 463 orang wanita menopause. Tujuan penelitian ini adalah untuk mengetahui bagaimana gambaran pengetahuan ibu menopause tentang gizi seimbang masa menopause di wilayah kerja puskesmas Awang Besar kecamatan Barabai kabupaten Hulu sungai Tengah tahun 2014. Desain penelitian ini deskriptif dengan pendekatan cross sectional. Populasi penelitian adalah semua ibu menopause yang bersedia menjadi responden di wilayah kerja Puskesmas Awang Besar kecamatan Barabai kabupaten Hulu Sungai Tengah sebanyak 463 orang. Pengambilan sampel menggunakan teknik simple random sampling sebanyak 83 responden. Hasil penelitian mayoritas responden pada rentang usia $48-55$ tahun dan mempunyai pengetahuan yang kurang terhadap gizi seimbang pada masa menopause yaitu sebanyak 47 orang responden (57,32\%). Kesimpulan tingkat pengetahuan ibu menopause tentang gizi seimbang di wilayah kerja Puskesmas Awang Besar kecamatan Barabai kabupaten Hulu Sungai Tengah masih kurang.
\end{abstract}

Kata Kunci: gizi seimbang, menopause, pengetahuan

\section{Knowledge of Menopause Woman about Balanced Nutrition in Menopause Period at The Regional of Puskesmas Awang Besar, Barabai, Hulu Sungai Tengah}

\begin{abstract}
Women were considered menopausal if the woman does not menstruate again within 12 months without any particular intervention. Data from the working area of health centers Awang Besar Hulu Sungai Tengah in 2014 there are 463 menopausal womens. The purposes of this study was to know knowledge of menopause woman about balanced nutrition in menopause period at the regional of Puskesmas Awang Besar, Barabai, Hulu Sungai Tengah. This study was used descriptive with cross-sectional design. The population are menopause women who willing to become respondents in Puskesmas Awang Besar, Barabai, Hulu Sungai Tengah. Samples was obtained by simple random sampling technique which consisted of 83 respondents. The results showed that majority of respondents in the range aged 48-55 years and have less knowledge about nutrition balanced during menopause were 47 respondents (57.32\%). In conclusion, there was less of knowledge about balanced nutrition in menopause period toward menopause woman in Puskesmas Awang Besar, Barabai, Hulu Sungai Tengah.
\end{abstract}

Keywords: balanced nutrition, menopause, knowledge

Info Artikel:

Artikel dikirim pada 20 Januari 2016

Artikel diterima pada 24 Februari 2016

DOI : http://dx.doi.org/10.21927/jnki.2016.4(1).49-53 


\section{PENDAHULUAN}

Data WHO di negara Asia, pada tahun 2025 jumlah wanita yang menopause akan meningkat dari 107 juta jiwa menjadi 373 juta jiwa, sedangkan menurut BPS tahun 2010 perkiraan kasar menunjukkan akan terdapat sekitar 30-40 juta wanita menopause dari seluruh jumlah penduduk Indonesia yang sebesar 240-250 juta jiwa pada tahun 2010(1).

Menopause adalah suatu peralihan dalam kehidupan wanita yang menunjukan bahwa ovarium telah berhenti menghasilkan sel telur, aktivitas menstruasi berkurang dan akhirnya berhenti, serta pembentukan hormon wanita (estrogen dan progesteron) yang berkurang, dan jika seorang wanita sudah tidak mengalami siklusnya selama minimal 12 bulan(2).

Menopause adalah sesuatu yang alami, untuk mencegah berbagai keluhan yang mungkin terjadi di masa menopause yang disebabkan oleh kekurangan hormon estrogen, dengan cara pengaturan menu makanan yang tepat sedini mungkin adalah salah satu jawaban yang tepat untuk mengatasi kekurangan hormon estrogen pada tubuh. Cara ini merupakan alternatif alamiah, yaitu dengan mengonsumsi ekstra estrogen yang banyak tergantung pada sejumlah bahan pangan. Ada senyawa alamiah dalam tumbuh-tumbuhan dan kacang-kacangan yang struktur kimianya mirip dengan hormon estrogen dan disinyalir akan menghasilkan efek seperti kerja estrogen, senyawa tersebut disebut fitoestrogen(3). Penurunan kadar hormon estrogen dan hormon progesterone berpengaruh terhadap suasana hati yang buruk sehingga sangat penting mengonsumsi makanan yang menyediakan nutrisi essensial untuk kesehatan fungsi otak(4).

Sindroma menopause dialami oleh banyak wanita hampir seluruh dunia sekitar 70-80\% wanita Eropa, $60 \%$ di Amerika, $57 \%$ di Malaysia, $18 \%$ di Cina dan $10 \%$ di Jepang dan di Indonesia dari beberapa data tampak bahwa salah satu faktor dari perbedaan jumlah tersebut adalah karena pola makannya. Pola makan wanita Eropa dan Amerika dapat lebih meningkatkan kadar estrogen di dalam tubuh dibandingkan dengan wanita Asia, sehingga ketika masa Menopause tiba jumlah estrogen drastis menurun menyebabkan tingginya sindroma menopause(5).

Data dari Badan Pusat Statistik Kalimantan Selatan tahun 2011 wanita yang mengalami menopause sekitar 266.801 orang. Menurut data dari wilayah kerja Puskesmas Awang Besar Kecamatan Barabai Kabupaten Hulu Sungai Tengah pada tahun 2014 ada 463 orang wanita menopause(1).
Berdasarkan hasil studi pendahuluan yang dilakukan pada bulan April tahun 2014 di wilayah kerja puskesmas Awang Besar Kecamatan Barabai Kabupaten Hulu Sungai Tengah tahun 2014 dari 10 wanita menopause, terdapat $7(70 \%)$ wanita menopause dengan tingkat pengetahuan yang rendah dan $2(20 \%)$ wanita menopause berpengetahuan cukup dan $1(10 \%)$ wanita menopause berpengetahuan baik. Berdasarkan latar belakang di atas maka peneliti tertarik untuk melakukan penelitian mengenai gambaran pengetahuan ibu menopause tentang gizi seimbang pada masa menopause di wilayah kerja puskesmas Awang Besar Kecamatan Barabai Kabupaten Hulu Sungai Tengah.

Secara umum tujuan dari penelitian ini untuk mengetahui gambaran pengetahuan ibu menopause tentang gizi seimbang pada masa menopause. Secara khusus untuk mengetahui tingkat pengetahuan ibu menopause pada masa menopause, untuk mengetahui gizi seimbang ibu menopause pada masa menopause, dan untuk mengetahui gizi seimbang pada masa menopause berdasarkan tingkat pengetahuan dengan status gizi di wilayah kerja Puskesmas Awang Besar Kecamatan Barabai Kabupaten Hulu Sungai Tengah Tahun 2014.

\section{BAHAN DAN METODE}

Jenis penelitian ini menggunakan desain deskriptif, bertujuan untuk melihat gambaran atau fenomena (termasuk kesehatan) yang terjadi di dalam suatu populasi tertentu. Penelitian yang dilakukan untuk mendeskripsikan atau menggambarkan suatu fenomena yang terjadi di dalam masyarakat(6). Penelitian ini menggambarkan secara objektif, yaitu suatu desain penelitian yang dilakukan dengan tujuan untuk mengetahui gambaran pengetahuan ibu menopause tentang gizi seimbang pada masa menopause. Populasi dalam penelitian ini adalah semua ibu menopause di wilayah kerja Puskesmas Awang Besar Kabupaten Hulu Sungai Tengah sebanyak 463 orang. Teknik pengambilan sampel yang digunakan dalam penelitian ini adalah simple random sampling, dilakukan secara acak tanpa memperhatikan strata yang ada dalam anggota populasi(7). Besarnya sampel dalam penelitian ini dihitung menggunakan rumus slovin, didapatkan hasil akhir sampel sebanyak 82 orang responden. Penelitian ini dilaksanakan di Wilayah Kerja Puskesmas Awang Besar Kabupaten Hulu Sungai Tengah sebanyak 4 desa dan 1 kelurahan yaitu desa Awang besar, desa Kayu Bawang, desa Gambah, desa Pajukungan dan kelurahan Bukat dari tanggal 4 sampai 6 juni tahun 2014. 


\section{HASIL DAN BAHASAN}

\section{Karakteristik Responden}

Responden dalam penelitian ini berjumlah 82 wanita menopause yang berada di wilayah kerja Puskesmas Awang Besar pada tahun 2014.

Tabel 1. Distribusi Frekuensi Responden Berdasarkan Umur, Ekonomi, Menerima Informasi, Tingkat Pengetahuan, dan IMT Wanita Menopause di Wilayah Kerja Puskesmas Awang Besar, Barabai, Hulu Sungai Tengah Tahun 2014

\begin{tabular}{lcc}
\hline \multicolumn{1}{c}{ Karakteristik } & f & $\%$ \\
\hline Umur (Tahun) & & \\
$\quad 48-55$ & 65 & 79,27 \\
$56-60$ & 9 & 10,98 \\
$\quad>60$ & 8 & 9,75 \\
Ekonomi & & \\
$\quad$ Rendah & 58 & 70,73 \\
$\quad$ Sedang & 22 & 26,83 \\
$\quad$ Tinggi & 2 & 2,44 \\
Menerima Informasi & & \\
$\quad$ Tidak Pernah & 70 & 85,37 \\
$\quad$ Pernah & 12 & 14,63 \\
Tingkat pengetahuan & & \\
$\quad$ Kurang & 47 & 57,32 \\
$\quad$ Cukup & 23 & 28,05 \\
$\quad$ Baik & 12 & 14,63 \\
IMT & & \\
$\quad$ Kurang (IMT <18,5) & 25 & 30,48 \\
$\quad$ Normal (IMT 18,5-25,0) & 30 & 36,59 \\
$\quad$ Lebih (IMT >25,0) & 27 & 32,93 \\
Total & 82 & 100 \\
\hline Sul
\end{tabular}

Sumber: Data Primer Tahun 2014

Berdasarkan Tabel 1 menunjukkan bahwa dari 82 orang responden, umur terbanyak berada pada rentang 48-55 tahun yaitu sebanyak 65 orang $(79,27 \%)$, tingkat ekonomi paling banyak adalah tingkat ekonomi rendah sebanyak 58 orang $(70,73 \%)$, kategori menerima informasi paling banyak adalah tidak pernah menerima informasi sebanyak 70 orang $(85,37 \%)$, untuk tingkat pengetahuan responden terbanyak adalah dengan tingkat pengetahuan kurang yaitu sebanyak 47 orang responden $(57,32 \%)$, sedangkan tingkat pengetahuan responden paling sedikit dengan tingkat pengetahuan baik yaitu sebanyak 12 orang responden $(14,63 \%)$, indeks massa tubuh (IMT) terbanyak adalah dengan kategori normal yaitu sebanyak 30 orang responden $(36,59 \%)$, sedangkan responden paling sedikit dengan kategori kurang yaitu berjumlah 25 orang responden $(30,48 \%)$.

Hasil penelitian Tabel 1 dapat digambarkan bahwa mayoritas berpengetahuan kurang hal ini disebabkan oleh berbagai faktor dan satu sama lain saling memengaruhi. Penelitian ini sejalan dengan penelitian Yeni, yang menyatakan bahwa dari 22 orang responden mayoritas berpengetahuan kurang sebanyak 12 orang $(54,5 \%)(8)$. Penelitian ini tidak sejalan dengan hasil penelitian Mufidah, yang menyatakan bahwa mayoritas responden berpengetahuan cukup sebanyak 31 orang (59,6\%) dari total 52 orang responden(9).

\section{Pengetahuan Ibu menopause berdasarkan Status Gizi}

Distribusi frekuensi responden berdasarkan tingkat pengetahuan dengan status gizi wanita menopause di wilayah kerja Puskesmas Awang Besar Kecamatan Barabai Kabupaten Hulu Sungai Tengah tahun 2014 disajikan pada Tabel 2.

Berdasarkan Tabel 2 menunjukkan bahwa dari 82 orang responden, responden terbanyak berpengetahuan kurang dengan status gizi kurang yaitu sebanyak 23 orang responden $(28,04 \%)$, sedangkan responden paling sedikit berpengetahuan baik dengan status gizi kurang yaitu sebanyak 2 orang responden $(2,44 \%)$.

Penelitian ini sesuai dengan teori Alimul, yang menyatakan bahwa seseorang dengan pengetahuan yang kurang tentang gizi seimbang akan berpengaruh terhadap pola konsumsi makanan(10). Seseorang dengan pengetahuan yang kurang tentang manfaat makanan bergizi akan kesulitan dalam memilih menu makanan, karena hal tersebut dapat disebabkan oleh kurangnya informasi sehingga dapat terjadi kesalahan dalam memahami kebutuhan gizi. Pengetahuan

Tabel 2. Distribusi Frekuensi Responden berdasarkan Tingkat Pengetahuan dengan Status Gizi Wanita Menopause di Wilayah Kerja Puskesmas Awang Besar, Barabai, Hulu Sungai Tengah Tahun 2014

\begin{tabular}{|c|c|c|c|c|c|c|c|c|}
\hline \multirow{2}{*}{ Pengetahuan } & \multicolumn{6}{|c|}{ Status Gizi } & \multirow{2}{*}{ Jumlah } & \multirow{2}{*}{$\%$} \\
\hline & Kurang & $\%$ & Normal & $\%$ & Lebih & $\%$ & & \\
\hline Kurang & 23 & 28,04 & 10 & 12,20 & 15 & 18,29 & 48 & 58,53 \\
\hline Cukup & 0 & 0 & 16 & 19,52 & 7 & 8,54 & 23 & 28,06 \\
\hline Baik & 2 & 2,44 & 4 & 4,88 & 5 & 6,09 & 11 & 13,41 \\
\hline Jumlah & 25 & 12,19 & 30 & 53,66 & 27 & 34,15 & 82 & $100 \%$ \\
\hline
\end{tabular}

Sumber: Data Primer Tahun 2014 
merupakan domain yang sangat penting untuk terbentuknya tindakan seseorang (overt behavior) karena dari pengalaman dan penelitian ternyata perilaku yang didasari oleh pengetahuan akan lebih baik dan lama daripada perilaku yang tidak didasari oleh pengetahuan (11).

Berdasarkan data Tabel 2, tingkat pengetahuan wanita menopause tentang gizi seimbang pada masa menopause di wilayah kerja Puskesmas Awang Besar berada dalam kategori kurang. Tingkat pengetahuan yang rendah terhadap gizi seimbang dikarenakan tingkat pendidikan wanita menopause dalam penelitian ini rendah. Sesuai dengan teori, yaitu pendidikan diperlukan untuk mendapatkan informasi, misalnya hal-hal yang menunjang kesehatan sehingga dapat meningkatkan kualitas hidup. Pada umumnya makin tinggi pendidikan seseorang makin mudah menerima informasi (12). Hal inilah yang menyebabkan wanita menopause dengan pendidikan yang rendah dan pengetahuan yang rendah memiliki masalah dalam pemenuhan gizi seimbang pada masa menopause seperti dalam penerimaan informasi karena rasa keingintahuan mereka kurang terhadap pemenuhan gizi seimbang pada masa menopause dan dapat memengaruhi pola konsumsi makanan. Karena Kemudahan untuk memperoleh suatu informasi dapat mempercepat seseorang memperoleh pengetahuan yang baru (13).

Tingkat ekonomi yang rendah juga berpengaruh terhadap penerimaan informasi wanita menopause tentang pemenuhan gizi seimbang pada masa menopause. Pada penelitian ini, sebanyak 58 orang responden $(70,73 \%)$ memiliki tingkat ekonomi yang rendah. Mereka lebih mementingkan pekerjaan mereka untuk memenuhi kebutuhan sehari-hari daripada mencari tahu bagaimana cara pemenuhan gizi seimbang pada masa menopause, dan hanya mementingkan bagaimana cara mengisi perut mereka daripada harus mencari tahu pemenuhan gizi seimbang yang dibutuhkan mereka setiap hari serta status ekonomi rendah juga menyebabkan mereka tidak bisa memenuhi kebutuhan. Kurangnya informasi menyebabkan kurangnya pengetahuan tentang gizi seimbang pada masa menopause.

Wanita menopause juga mengalami penurunan kadar hormone estrogen di dalam tubuhnya yang memengaruhi susunan saraf pusat atau otak yang menyebabkan kesulitan berkonsentrasi dan lupa akan kejadian yang pernah dialaminya. Hal inilah yang menyebabkan wanita menopause sukar memahami apa yang disampaikan dalam penerimaan informasi sehingga dapat menyebabkan kurangnya pengetahuan tentang gizi seimbang masa menopause (14).
Banyak faktor yang mempengaruhi pengetahuan ibu menopause, sehingga dibutuhkan kesadaran yang tinggi untuk memperoleh informasi karena semakin tinggi kesadaran untuk memperoleh informasi maka akan meningkatkan pengetahuan. Banyaknya informasi-informasi yang disajikan melalui media cetak, media eloktronik dan juga dari tenaga kesehatan diharapkan juga dapat meningkatkan pengetahuan masyarakat tentang kesehatan khususnya tentang kebutuhan gizi pada masa menopause sehingga masyarakat mempunyai pengetahuan yang baik.

Pengetahuan yang baik tentang kebutuhan gizi pada masa menopause dapat mengurangi dampak negatif pada masa menopause, karena dengan semakin baiknya pengetahuan wanita menopause tersebut, ia akan mampu memilah makanan ataupun asupan gizi pada dirinya yang diperlukan ataupun yang tidak dan yang sehat ataupun tidak. Pemenuhan gizi seimbang seperti makan makanan yang sehat, rendah lemak, tinggi serat, banyak mengandung vitamin dan mineral apalagi menambah bahan makanan yang mengandung fitoestrogen seperti kedelai dan pepaya. Karena pada masa ini wanita mengalami penurunan hormone estrogen, yang menimbulkan rasa ketidaknyamanan dalam kehidupan sehari-hari. Oleh karena itu, pengetahuan dan informasi sangat penting kepada wanita menopause tentang pemenuhan gizi seimbang masa menopause sehingga ibu-ibu tersebut bisa menjalani masa tuanya dengan bahagia dan akhirnya dapat meningkatkan usia harapan hidup di Indonesia.

\section{SIMPULAN DAN SARAN}

Berdasarkan hasil penelitian terhadap gambaran pengetahuan ibu menopause tentang gizi seimbang pada masa menopause di wilayah kerja Puskesmas Awang Besar Kecamatan Barabai Kabupaten Hulu Sungai Tengah mayoritas responden pada rentang usia 48-55 tahun dan mempunyai pengetahuan yang kurang terhadap gizi seimbang pada masa menopause yaitu sebanyak 47 orang responden $(57,32 \%)$, berpengetahuan cukup sebanyak 23 orang responden $(28,05 \%)$ dan yang berpengetahuan baik sebanyak 12 orang responden (14,63\%) dengan jumlah sampel sebanyak 82 orang responden.

Diharapkan kepada semua ibu menopause yang berpengetahuan kurang untuk meningkatkan pengetahuannya dengan cara mencari informasi yang lebih akurat tentang kesehatan khususnya tentang menopause baik dari ibu yang sudah berpengalaman, media cetak, dan tenaga kesehatan. Diharapkan kepada fasilitas kesehatan untuk semakin 
meningkatkan pengetahuan ibu menopause tentang kebutuhan gizi dengan cara memberikan penyuluhanpenyuluhan

\section{RUJUKAN}

1. Badan Pusat Statistik. Tabel Jumlah Penduduk Menurut Kelompok Umur, Jenis Kelamin, Provinsi, dan Kabupaten/Kota [Internet]. 2011 [cited 2014 Mar 12]. Available from: http:// www.datastatistikindonesia.com/component/ option,com_tabel/kat, 1/ idtabel,116/ltemid, 165/

2. Hidayat AA. Pengantar Kebutuhan Dasar Manusia. Jakarta: Salemba Medika; 2006.

3. Icesmi SK, Margareth ZH. Kehamilan, Persalinan, dan Nifas. Yogyakarta: Nuha Medika; 2013.

4. Mulyati, Siti N. Menopause. y: Nuha Medika; 2013.

5. Proverawati A. Menopause dan Sindrom Premenopause. Yogyakarta: Nuha Medika; 2010.

6. Notoatmodjo S. Metodologi Penelitian Kesehatan. Jakarta: Rineka Cipta; 2010.
7. Setiawan A, Saryono. Metodologi Penelitian Kebidanan. 3rd ed. Yogyakarta: Nuha Medika; 2011.

8. Yeni M. Gambaran Pengetahuan Ibu Menopuase tentang Kebutuhan Gizi pada Masa Menopause di Lingkungan II Kelurahan Tanjung Gusta Medan Tahun 2013. Medan; 2013.

9. Mufidah DW. Tingkat Pengetahuan Ibu Menopause tentang Gizi Menopause di Dusun Pandansari Desa Jururejo Kabupaten Ngawi Tahun 2013. Surakarta; 2013.

10. Hidayat AA. Metode Penelitian Keperawatan dan Teknik Analisis Data. Jakarta: Salemba Medika; 2009.

11. Notoatmodjo S. Kesehatan Masyarakat. revisi. Jakarta: Rineka Cipta; 2011.

12. Wawan A, Dewi M. Teori dan Pengukuran Pengetahuan, Sikap, dan Perilaku Manusia. Yogyakarta: Nuha Medika; 2010.

13. Mubarak WI. Promosi Kesehatan untuk Kebidanan. Jakarta: Salemba Medika; 2011.

14. Kumalasari I, Andhyantoro I. Kesehatan Reproduksi. Jakarta: Salemba Medika; 2012. 